\title{
Placental Growth Factor Promotes Metastases of Non-Small Cell Lung Cancer Through MMP9
}

\author{
Wei Zhang ${ }^{\text {a Ting Zhang }}{ }^{\mathrm{b}}$ Yuqing Lou ${ }^{\mathrm{a}}$ Bo Yan ${ }^{\mathrm{a}}$ Shaohua Cui ${ }^{\mathrm{a}}$ Liyan Jiang ${ }^{\mathrm{a}}$ \\ Baohui Hana \\ aDepartment of Pulmonary Medicine, Shanghai Chest Hospital, Shanghai Jiaotong University, Shanghai, \\ ${ }^{b}$ Department of Nuclear Medicine, the 309 th Hospital of Chinese People's Liberation Army, Beijing, \\ China
}

\section{Key Words}

Placental growth factor (PLGF) • Matrix metalloproteinase 9 (MMP9) • Non-small cell lung cancer (NSCLC) • Metastases

\begin{abstract}
Background/Aims: Neovascularization and invasion coordinate cancer metastases in nonsmall cell lung cancer (NSCLC). However, the underlying molecular mechanisms are poorly understood. Recently, a substantial role of placental growth factor (PLGF) in cancer cell invasion has been acknowledged in several types of cancer, whereas a possible involvement of PLGF in the metastases of NSCLC has not been studied. Methods: Here, we analyzed the levels of PLGF and matrix metalloproteinase 9 (MMP9) in NSCLC specimens. We modified either PLGF or MMP9 levels in a NSCLC cell line A549, and examined the effects on the levels of MMP9 and PLGF. The cell invasiveness was quantified in a transwell cell migration assay. Pathway inhibitors were applied to determine the molecular mechanisms underlying the control of MMP9 by PLGF. Results: We found that PLGF and MMP9 levels both significantly increased in the NSCLC specimens and were strongly correlated. Overexpression of PLGF in NSCLC cells increased the levels of MMP9 and cell invasiveness, while inhibition of PLGF in NSCLC cells decreased the levels of MMP9 and cell invasiveness. However, modification of MMP9 levels in NSCLC cells did not alter the levels of PLGF. These data suggest that PLGF may regulate MMP9 in NSCLC cells, but not vice versa. Moreover, inhibition of MMP9 in PLGF-overexpressing NSCLC cells abolished the effects of PLGF on cell invasiveness, suggesting that PLGF increases cell invasion via MMP9. Furthermore, suppression of MAPK-p38, but not suppression of either MAPK-p42/ p44, or PI3k, or JNK signaling, substantially abolished the effect of PLGF on MMP9, suggesting that PLGF may activate MMP9 via MAPK-p38 signaling pathway. Conclusion: PLGF-stimulated cancer invasion may be mediated through its effects on MMP9 activation in NSCLC cells.
\end{abstract}

W. Zhang and T. Zhang contributed equally to this work.

Baohui Han

KARGER 125
Department of Pulmonary Medicine, Shanghai Chest Hospital, Shanghai Jiaotong University, 241 Huaihai West Road, Shanghai 200030, (China)

Tel. +8662821990, E-Mail hanbao_hui@163.com 


\section{Cellular Physiology Cell Physiol Biochem 2015;37:1210-1218

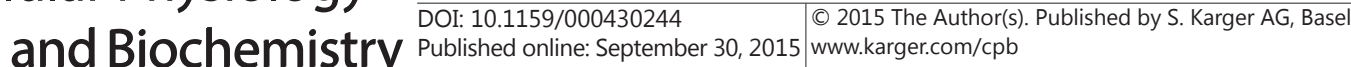 \\ Zhang et al.: PLGF Regulates Metastasis of NSCLC via MMP9}

\section{Introduction}

Non-small cell lung cancer (NSCLC) is a prevalent lung cancer, which has been catalogued into three subtypes: squamous cell carcinoma, large cell carcinoma, and adenocarcinoma [1-4]. Most NSCLCs are fast-growing, and are resistant to combined chemotherapy and radiation therapy [1-5]. Hence, it is critical to develop novel therapy to suppress the growth and invasion of NSCLCs [6-9].

Cancer-related angiogenesis provides oxygen and nutrients to tumor growth and metastasis, which are important for cancer invasion and metastasis. Cancer cells not only secrete proteinases to break through protein barriers in the extracellular matrix [10], but also secrete angiogenic factors to promote vessel formation $[11,12]$. Vascular endothelial growth factor (VEGF) family is the most important signal protein produced by cells that stimulates vasculogenesis and angiogenesis [13]. The VEGF family is composed of six secreted proteins: VEGF-a, VEGF-b, VEGF-c, VEGF-d, VEGF-e and placental growth factor (PLGF) [14-16]. PLGF plays an important role in the pathological angiogenesis, in a coordinated way with other VEGF family members [17-20].

The matrix metalloproteinase (MMP) family members are involved in the breakdown of extracellular matrix in normal physiological processes, such as embryonic development, reproduction, and tissue remodeling, as well as in disease processes, including cancer metastasis [21,22]. MMP9 is a member of MMP family, and is secreted by various cancer cells to break down extracellular matrix [23-25]. Overexpression of MMP9 has been reported to facilitate metastatic spread of different cancer cells and appears to be an important molecule to directly promote NSCLC metastasis. Nevertheless, whether MMP9 may be regulated by angiogenic factors in NSCLC cells has not been examined before.

Recently, PLGF was shown to regulate MMP3 or MMP9 to control the metastasis of larynx carcinoma, esophageal cancer and oral squamous cell carcinoma [26-29], as the first reports to show an interaction between angiogenic factors and proteinases for extracellular matrix breakdown. However, such regulatory machinery in NSCLC has not been determined.

Here, we found that PLGF and MMP9 levels both significantly increased in the NSCLC specimens and were strongly correlated. PLGF regulated MMP9 in NSCLC cells, but not vice versa. Moreover, inhibition of MMP9 in PLGF-overexpressing NSCLC cells abolished the effects of PLGF on cell invasiveness. Furthermore, suppression of MAPK-p38, but not suppression of either MAPK-p42/p44, or PI3k, or JNK signaling, substantially abolished the effect of PLGF on MMP9.

\section{Materials and Methods}

\section{Patient tissue specimens}

A total of 35 resected specimens from NSCLC patients were collected for this study. All specimens had been histologically and clinically diagnosed at the Department of Pulmonary Medicine of Shanghai Chest Hospital from 2010 to 2014. For the use of these clinical materials for research purposes, prior patient's consents and approval were collected and approved by the Institutional Research Ethics Committee.

\section{Cell lines and reagents}

A549 and SW900 are 2 human NSCLC lines were all purchased from American Type Culture Collection (ATCC, Rockville, MD, USA), and were cultured in Dulbecco's modified Eagle's media (DMEM, Invitrogen, Carlsbad, CA, USA) supplemented with 15\% fetal bovine serum (Invitrogen). A549 was first developed in 1972 by Dr. Giard through the removal and culturing of cancerous lung tissue in the explanted tumor a of 58-year-old caucasian male [30]. Another cell line SW900 was also used in the current study, and since we got similar results compared to A549, only data from A549 has been shown. Inhibitors PD98058 (used at a dose of $10 \mu \mathrm{mol} / \mathrm{l}$ ), LY294002 (used at a dose of $20 \mu \mathrm{mol} / \mathrm{l}$ ), SB203580 (used at a dose of $1 \mu \mathrm{mol} / \mathrm{l}$ ) and SP600125 (used at a dose of $10 \mu \mathrm{mol} / \mathrm{l}$ ) were all purchased from Sigma-Aldrich (St. Louis, MO, USA). 


\section{Cellular Physiology Cell Physiol Biochem 2015;37:1210-1218

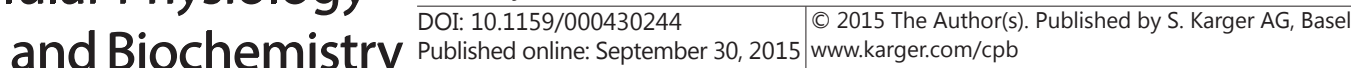 \\ Zhang et al.: PLGF Regulates Metastasis of NSCLC via MMPg}

Transfection of NSCLC cells

NSCLC cells were transfected with a PLGF-overexpressing plasmid (PLGF), or a small short hairpin interfering RNA for PLGF (shPLGF), or MMP9-overexpressing plasmid (MMP9), or a small short hairpin interfering RNA for MMP9 (shMMP9), as has been previously described [31]. Cells transfected with plasmids carrying a scrambled sequence (scr) were used as a control. Transfection efficiency is nearly $100 \%$.

Transwell matrix penetration assay

Cells $\left(4 \times 10^{5}\right)$ were plated into the top side of polycarbonate transwell filter coated with Matrigel in the upper chamber of the BioCoatTM Invasion Chambers (BD, Bedford, MA, USA) and incubated at $37^{\circ} \mathrm{C}$ for 22 hours. The cells inside the upper chamber were then removed with cotton swabs. Migratory and invasive cells on the lower membrane surface were fixed, stained with hematoxylin, and counted for 10 random 100X fields per well. Cell counts are expressed as the mean number of cells per field of view. Five independent experiments were performed and the data are presented as mean \pm standard deviation (SD).

\section{ELISA assay}

The concentration of MMP9 in the conditioned media from cultured cells was determined by a MMP9 ELISA Kit (Sigma-Aldrich). The concentration of PLGF in the cultured cells was determined by a PLGF ELISA kit (Raybio, Norcross, GA, USA). ELISAs were performed according to the instructions of the manufacturer. Briefly, the collected conditioned media was added to a well coated with MMP9/PLGF polyclonal antibody, and then immunosorbented by biotinylated monoclonal anti-human MMP9/PLGF antibody at room temperature for 2 hours. The color development catalyzed by horseradish peroxidase was terminated with $2.5 \mathrm{~mol} / \mathrm{l}$ sulfuric acid and the absorption was measured at $450 \mathrm{~nm}$. The protein concentration was determined by comparing the relative absorbance of the samples with the standards.

\section{Western blot}

The protein was extracted from the resected NSCLC from the patient specimen, or from cultured NSCLC cells in RIPA lysis buffer (1\% NP40, 0.1\% SDS, $100 \mu \mathrm{g} / \mathrm{ml}$ phenylmethylsulfonyl fluoride, $0.5 \%$ sodium deoxycholate, in PBS) on ice. The supernatants were collected after centrifugation at $12000 \times \mathrm{g}$ at $4^{\circ} \mathrm{C}$ for $20 \mathrm{~min}$. Protein concentration was determined using a BCA protein assay kit (Bio-rad, China), and whole lysates were mixed with $4 \times$ SDS loading buffer $(125 \mathrm{mmol} / \mathrm{l}$ Tris-HCl, 4\% SDS, 20\% glycerol, $100 \mathrm{mmol} / \mathrm{L}$ DTT, and $0.2 \%$ bromophenol blue) at a ratio of $1: 3$. Samples were heated at $100{ }^{\circ} \mathrm{C}$ for 5 min and were separated on SDS-polyacrylamide gels. The separated proteins were then transferred to a PVDF membrane. The membrane blots were first probed with a primary antibody. After incubation with horseradish peroxidase-conjugated second antibody, autoradiograms were prepared using the enhanced chemiluminescent system to visualize the protein antigen. The signals were recorded using X-ray film. Primary antibodies were anti-PLGF, anti-MMP9 and anti- $\alpha$-tubulin (all purchased from Cell Signaling, San Jose, CA, USA). $\alpha$-tubulin was used as a protein loading control. Secondary antibody is HRP-conjugated anti-rabbit (Jackson ImmunoResearch Labs, West Grove, PA, USA). Images shown in the figure were representative from 5 repeats. Densitometry of Western blots was quantified with NIH ImageJ software (Bethesda, MA, USA). The protein levels were first normalized to loading controls, and then normalized to experimental controls.

\section{$R T-q P C R$}

RNA was extracted from cultured cells with RNeasy kit (Qiagen, Hilden, Germany) and used for cDNA synthesis. Quantitative PCR (RT-qPCR) were performed in duplicates with QuantiTect SYBR Green PCR Kit (Qiagen). All primers were purchased from Qiagen. Values of genes were normalized against $\alpha$-tubulin and then compared to controls.

\section{Statistical analysis}

All statistical analyses were carried out using the SPSS 19.0 statistical software package. All data were statistically analyzed using one-way ANOVA with a Bonferoni Correction. Bivariate correlations between PLGF and MMP9 levels were calculated by Spearman's Rank Correlation Coefficients. All values are depicted as mean \pm standard deviation from 5 individuals and are considered significant if $\mathrm{p}<0.05$. The figures were generated in Prism 6.0 (GraphPad Software Inc, USA).

\section{KARGER}




\section{\begin{tabular}{ll} 
Cellular Physiology & \multicolumn{1}{c}{ Cell Physiol Biochem 2015;37:1210-1218 } \\
DOI: 10.1159/000430244 & 0 2015 The Author(s). Published by S. Karger AG, Basel
\end{tabular} and Biochemistry Published online: September 30, 2015 www.karger.com/cpb \\ Zhang et al.: PLGF Regulates Metastasis of NSCLC via MMP9}

\section{Results}

NSCLC patients have increased serum PLGF levels, which are correlated with MMP9 levels in NSCLC specimens

We examined the levels of serum PLGF in 30 NSCLC patients, compared to 30 cases without NSCLC or other cancers. We found that NSCLC patients have increased serum PLGF levels (Fig. 1A). Since MMP9 has been shown to increase in NSCLC and is critical for cancer metastases, we analyzed the relationship between PLGF and MMP9 in 30 NSCLC specimens. We detected a strong correlation between serum PLGF and tissue MMP9 levels (Fig. 1B, $\mathrm{r}=0.85, \mathrm{p}<0.0001)$. In addition, patients with metastasis of the primary NSCLC expressed significantly higher levels of MMP9 (Fig. 1C) and PLGF (Fig. 1D). These data suggest a causal link between PLGF and MMP9 in NSCLC, and a possible role of PLGF and MMP9 in the metastases of NSCLC.

PLGF activates MMP9-mediated cell invasion in NSCLC cells

Then we analyzed 2 human NSCLC cell lines, A549 and SW900, to examine whether expression of PLGF and MMP9 may affect each other. Since we achieved very similar data from both lines, which ruled out a possibility of cell-line dependent results, we only showed data from A549 here. We transfected the NSCLC cells with either a PLGF expressing plasmid (PLGF), or a small short hairpin interfering RNA for PLGF (shPLGF), or a control scr plasmid (scr). First, the modification of PLGF in A549 cells was confirmed by RT-qPCR (Fig. 2A), and by Western blot (Fig. 2B). Then, we found that overexpression of PLGF in A549 cells increased MMP9 expression, while inhibition of PLGF in A549 cells decreased MMP9 expression, by RTqPCR (Fig.2C), by Western blot (Fig. 2B) and by ELISA on secreted protein in the conditioned media (Fig. 2D). These data suggest that the MMP9 are regulated by PLGF in NSCLC cells.

Fig. 1. PLGF and MMP9 levels in the metastasis in NSCLC patients and their correlation. (A) Serum PLGF levels were measured by ELISA in 30 NSCLC patients, compared to 30 control non-NSCLC cases. (B) A strong correlation between PLGF and MMP9 was detected $(\gamma=$ 0.85; $\mathrm{P}<0.0001)$, using 30 NSCLC cases. (C-D) Patients with metastasis of the primary NSCLC had significantly higher levels of MMP9 (B) and PLGF (C). ${ }^{*} \mathrm{p}<0.05 . \mathrm{N}=60$.
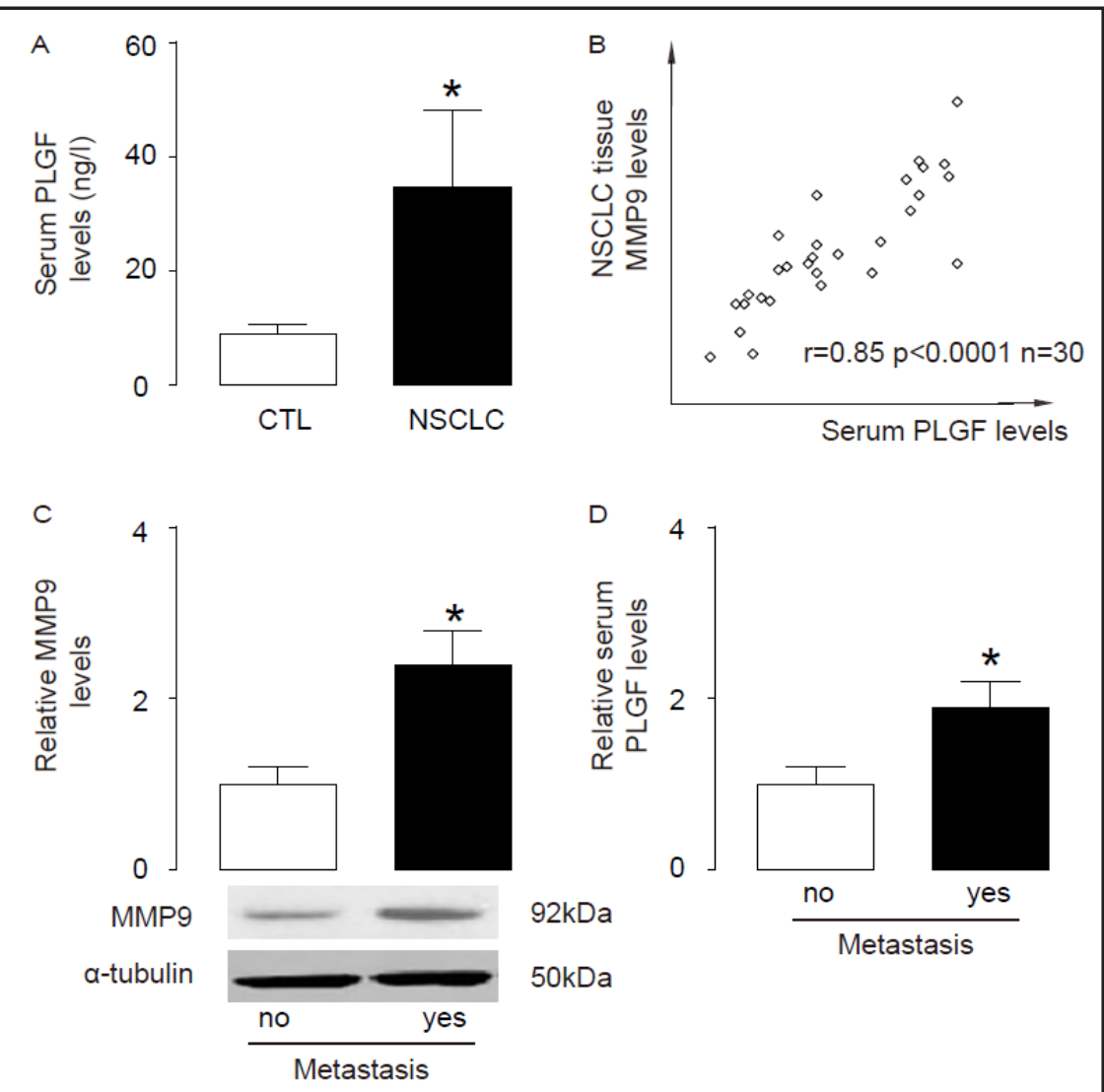
Fig. 2. PLGF regulates MMP9 in NSCLC cells. A human NSCLC cell line, A549, was transfected with either a PLGF expressing plasmid (PLGF), or shPLGF, or scr plasmid (scr). (A) RT-qPCR for PLGF. (B) Western blot for PLGF and MMP9. (C) RT-qPCR for MMP9. (D) ELISA for secreted MMP9. (E) The invasion ability of the A549 cells in a transwell cell migration assay. ${ }^{*} \mathrm{p}<0.05$. $\mathrm{N}=5$.

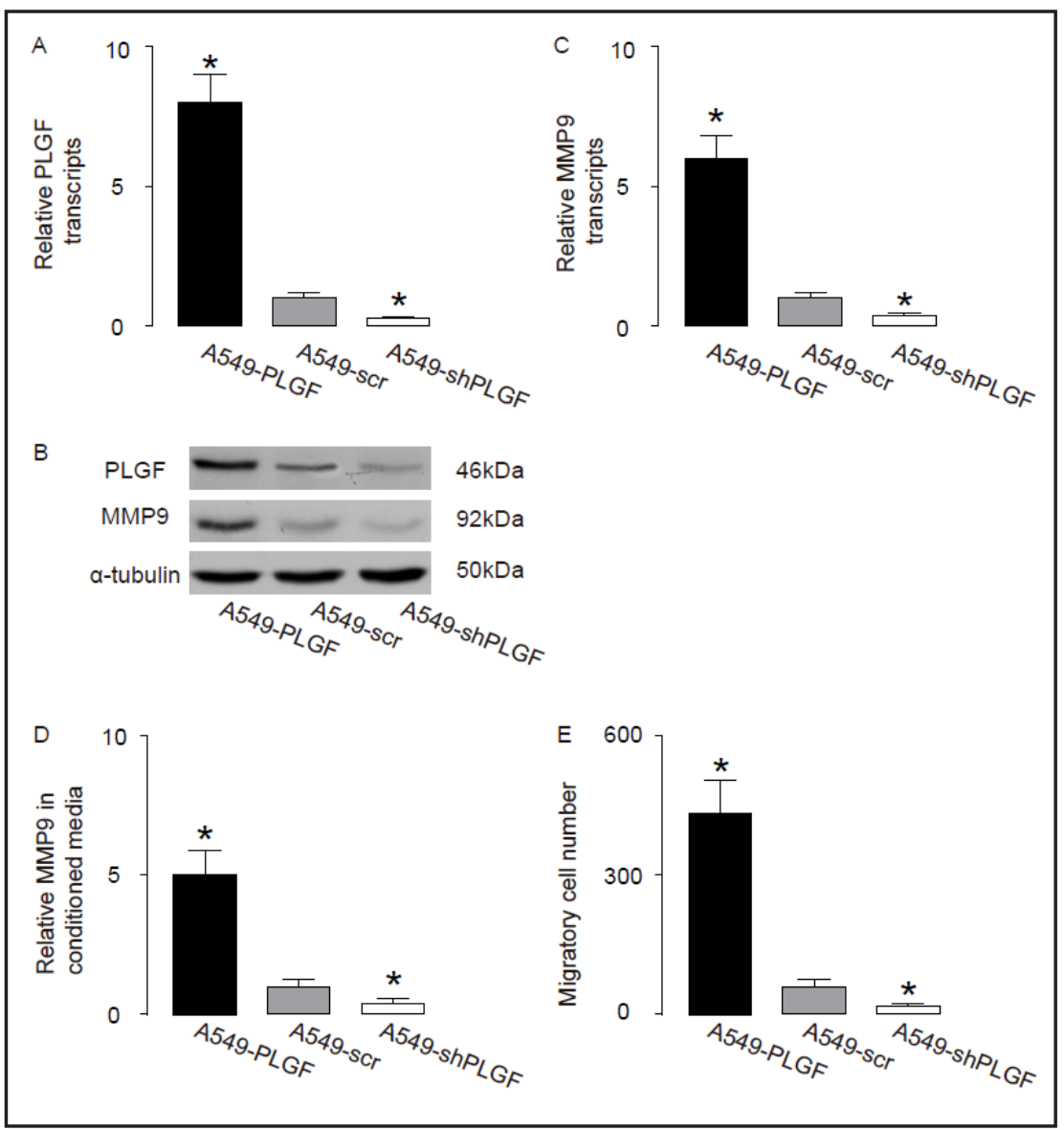

Next, we examined whether the modification of PLGF levels may alter the invasion ability of the A549 cells in a transwell cell migration assay. We found that PLGF overexpression significantly increased the invasiveness of A549 cells, while inhibition of PLGF significantly decreased the invasiveness of A549 cells (Fig. 2E). These data suggest that PLGF regulates MMP9 levels in NSCLC cells to control the cell metastases.

\section{PLGF is not regulated by MMP9 in NSCLC cells}

Next, we examined whether MMP9 may similarly affect the PLGF in NSCLC cells. For this purpose, we transfected the NSCLC cells with either a MMP9 expressing plasmid (MMP9), or a small short hairpin interfering RNA for MMP9 (shMMP9), or a control scr plasmid (scr). First, the modification of MMP9 in A549 cells was confirmed by RT-qPCR (Fig. 3A), and by Western blot (Fig. 3B). We found that the adaptation of MMP9 levels in NSCLC cells did not alter the levels of PLGF, by RT-qPCR (Fig. 3C), by Western blot (Fig. 3B) and by ELISA on secreted protein in the conditioned media (Fig. 3D), suggesting that PLGF is not regulated by MMP9. Next, we examined whether the modification of MMP9 levels may alter the invasion ability of the A549 cells in a transwell cell migration assay. We found that MMP9 overexpression significantly increased the invasiveness of A549 cells, while inhibition of MMP9 in A549 cells decreased it significantly (Fig. 3E). Apparently, the alteration in NSCLC invasiveness resulted from the changes in MMP9 itself, rather than PLGF.

\section{PLGF regulates cell invasion through MMP9}

In order to confirm the increases in cell invasion by PLGF overexpression is through MMP9, we transfected the NSCLC cells with both PLGF expressing plasmid (PLGF) and a small short hairpin interfering RNA for MMP9 (shMMP9). The increases in MMP9 by PLGF overexpression were abolished in these cells (A549-PLGF-shMMP9), by RT-qPCR (Fig. 4A), 
Fig. 3. PLGF is not regulated by MMP9. A549 cells were transfected with either a MMP9 expressing plasmid (MMP9), or shMMP9, or scr plasmid (scr). (A) RT-qPCR for MMP9. (B) Western blot for PLGF and MMP9. (C) RT-qPCR for PLGF. (D) ELISA for secreted PLGF. (E) The invasion ability of the A549 cells in a transwell cell migration assay. ${ }^{*} \mathrm{p}<0.05$. NS: non-significant. $\mathrm{N}=5$.
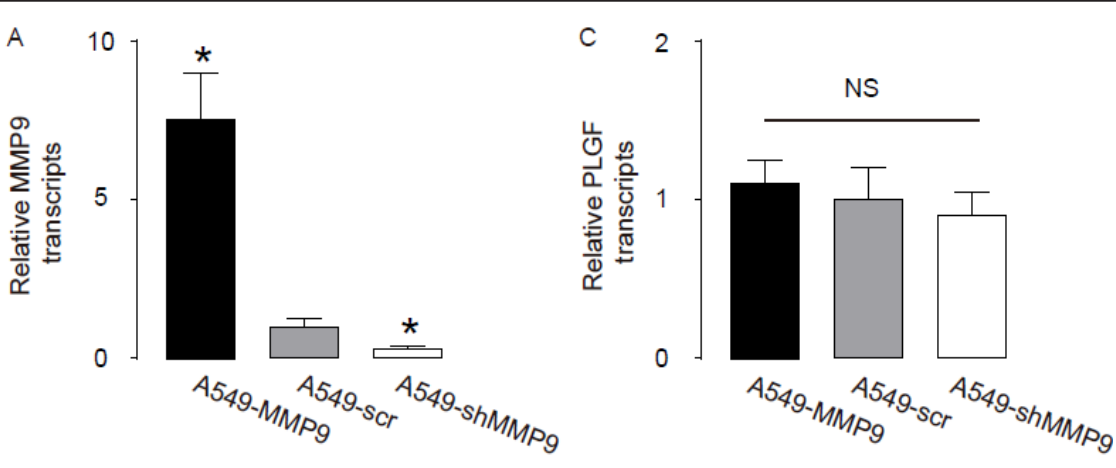

B
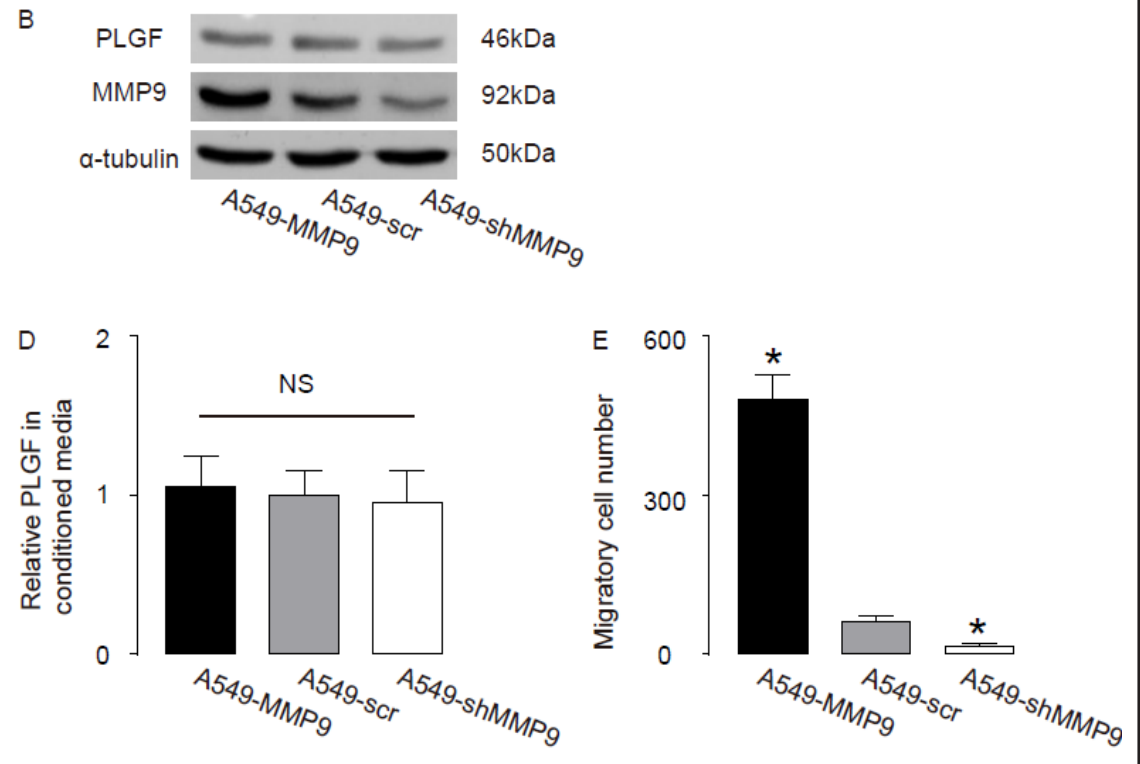

by Western blot (Fig. 4B) and by ELISA on secreted protein in the conditioned media (Fig. 4C). Next, we examined the cell invasiveness of these A549-PLGF-shMMP9 cells in a transwell cell migration assay. We found that MMP9 suppression completely abolished the increases in invasiveness by PLGF overexpression (Fig. 4D), suggesting that PLGF regulates cell invasion through MMP9.

\section{PLGF activates MMP9 through p38-MAPK signaling pathway}

We then analyzed the signaling pathway through which PLGF regulates MMP9. Application of a specific p38-MAPK signaling pathway inhibitor SB203580, but not application of either a specific p42/p44-MAPK signaling pathway inhibitor PD98059, or a specific PI3k/Akt signaling pathway inhibitor LY294002, or a specific JNK pathway inhibitor SP600125, to PLGF-overexpressing A549 cells substantially abolished the effect of PLGF in activating MMP9, by RT-qPCR (Fig. 4A), by Western blot (Fig. 4B), and by ELISA on secreted protein in conditioned media (Fig. 4C), resulting in a significantly decrease in the PLGFinduced augment in NSCLC cell invasiveness (Fig. 4D). These data suggest that PLGF may increase expression of MMP9 through p38-MAPK signaling pathway in NSCLC.

\section{Discussion}

Understanding the molecular mechanism underlying cancer neovascularization and metastasis may substantially improve the prevention and treatment of NSCLC. Angiogenesis is a critical process by which NSCLC invade and migrate. NSCLC cells, like other tumor cells, not 
Fig. 4. PLGF regulates MMP9 through ERK/MAPK signaling pathway. We transfected the A549 cells with both PLGF expressing plasmid (PLGF) and a small short hairpin interfering RNA for MMP9 (shMMP9), resulting in A549-PLGFshMMP9 cells. We also used either a specific p38-MAPK signaling pathway inhibitor SB203580 (SB), or a specific p42/p44-MAPK signaling pathway inhibitor PD98059 (PD), or a specific PI3k/Akt signaling pathway inhibitor LY294002 (LY), or a specific JNK pathway inhibitor SP600125 (SP), to PLGF-overexpressing A549 cells. (A) RT-qPCR for MMP9. (B) Western blot for PLGF and MMP9. (C) ELISA for secreted MMP9. (D) The invasion ability of the A549 cells in a transwell cell migration assay. ${ }^{*} \mathrm{p}<0.05$. NS: non-significant. $\mathrm{N}=5$.
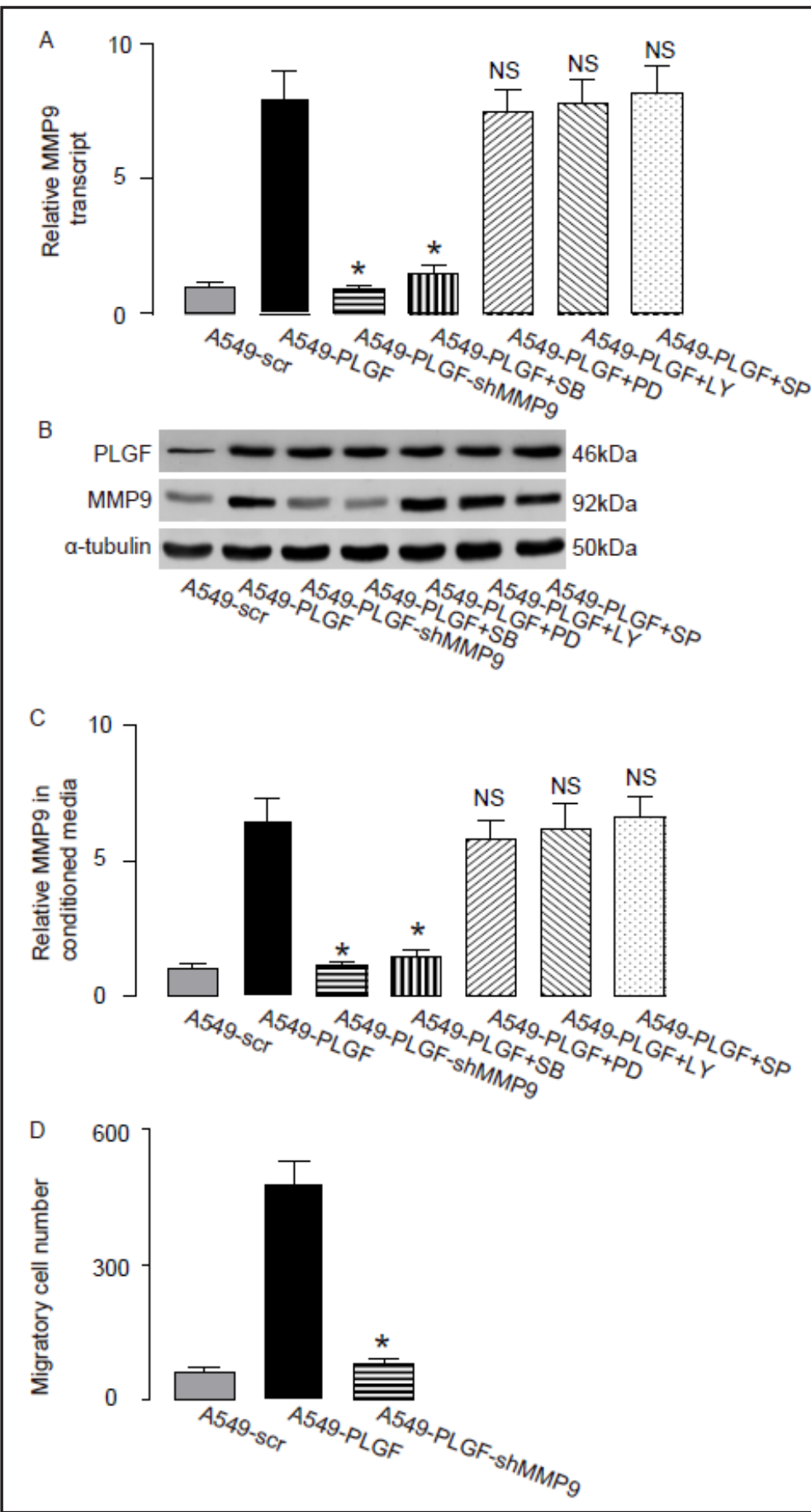

only secrete angiogenic molecules like PLGF to induce new vessel formation, but also secrete MMPs to degrade extracellular matrix [32]. Although both angiogenesis and extracellular matrix breakdown are equally important for cancer angiogenesis and metastasis, little is known about the interaction of angiogenic factors and MMPs. Since several recent reports have shown a regulation pathway between PLGF and MMPs in the metastasis of some cancers other than NSCLC, we were prompted to examine whether similar regulatory pathway may exist in NSCLC as well.

Here we found strong correlation of PLGF and MMP9 levels in the NSCLC. Moreover, significant higher levels of PLGF and MMP9 were detected in the NSCLC from the patients with metastasis of the primary cancer, suggesting a possible involvement of PLGF and MMP9 


\section{Cellular Physiology Cell Physiol Biochem 2015;37:1210-1218 and Biochemistry Published online: September 30,2015 $\begin{aligned} & \text { (c) 2015 The Author(s). Published by S. Karger AG, Basel } \\ & \text { www.karger.com/cpb }\end{aligned}$ \\ Zhang et al.: PLGF Regulates Metastasis of NSCLC via MMP9}

in the metastasis of NSCLC. To prove this hypothesis, we used 2 human NSCLC cell lines to examine the interaction of PLGF and MMP9. In both lines, we reached very similar results in the scope of the current study. These data thus ruled out a possibility of cell-line dependence. We only showed data from A549 here.

We found that overexpression of PLGF in NSCLC cells increased expression of MMP9, while inhibition of PLGF in NSCLC cells decreased expression of MMP9. However, neither overexpression, nor inhibition of MMP9 in NSCLC cells affected expression of PLGF. These data suggest that PLGF may function upstream of MMP9 in NSCLC cells. Since MMP9 is a well-known factor to facilitate cell invasion, we thus studied the regulation pathway between PLGF and MMP9. For this purpose, we applied specific signal pathway inhibitors to PLGFoverexpressing NSCLC cells, and found that only application of a specific p39-MAPK inhibitor substantially abolished the effect of PLGF on MMP9 activation and cell invasion, suggesting that PLGF may activate MMP9 through p38-MAPK signaling pathway.

Anti-PLGF has been applied in the clinical trials to inhibit cancer-related angiogenesis, but our understanding of its precise function remains limited. Our study, together with recent work showing a control panel of PLGF/MMPs in some cancers, illustrates a novel model of the molecular mechanism underlying the angiogenesis and invasiveness of cancer cells. Further delineation of the underlying molecular mechanism may substantially improve our understanding of the cancer metastasis regulation, especially those in NSCLC.

\section{Acknowledgments}

This work was financially supported by National Nature Science Foundation of China (no: 81402378).

\section{Disclosure Statement}

The authors have declared that no competing interests exist.

\section{References}

1 Caramori G, Casolari P, Cavallesco GN, Giuffre S, Adcock I, Papi A: Mechanisms involved in lung cancer development in copd. Int J Biochem Cell Biol 2011;43:1030-1044.

2 Buttery RC, Rintoul RC, Sethi T: Small cell lung cancer: The importance of the extracellular matrix. Int J Biochem Cell Biol 2004;36:1154-1160.

3 Jian H, Zhao Y, Liu B, Lu S: Sema4b inhibits mmp9 to prevent metastasis of non-small cell lung cancer. Tumour Biol 2014;35:11051-11056.

4 Jian H, Zhao Y, Liu B, Lu S: Sema4b inhibits growth of non-small cell lung cancer in vitro and in vivo. Cell Signal 2015;27:1208-1213.

5 Pei J, Lou Y, Zhong R, Han B: Mmp9 activation triggered by epidermal growth factor induced foxo1 nuclear exclusion in non-small cell lung cancer. Tumour Biol 2014;35:6673-6678.

6 Niu H, Wu B, Jiang H, Li H, Zhang Y, Peng Y, He P: Mechanisms of rhogdi2 mediated lung cancer epithelialmesenchymal transition suppression. Cell Physiol Biochem 2014;34:2007-2016.

7 Xiong Y, Ye T, Wang M, Xia Y, Wang N, Song X, Wang F, Liu L, Zhu Y, Yang F, Wei Y, Yu L: A novel cinnamide ylt26 induces breast cancer cells apoptosis via ros-mitochondrial apoptotic pathway in vitro and inhibits lung metastasis in vivo. Cell Physiol Biochem 2014;34:1863-1876.

8 Yun M, Kim EO, Lee D, Kim JH, Kim J, Lee H, Lee J, Kim SH: Melatonin sensitizes h1975 non-small-cell lung cancer cells harboring a t790m-targeted epidermal growth factor receptor mutation to the tyrosine kinase inhibitor gefitinib. Cell Physiol Biochem 2014;34:865-872.

9 Sun LX, Li WD, Lin ZB, Duan XS, Li XF, Yang N, Lan TF, Li M, Sun Y, Yu M, Lu J: Protection against lung cancer patient plasma-induced lymphocyte suppression by ganoderma lucidum polysaccharides. Cell Physiol Biochem 2014;33:289-299.

10 Dufour A, Overall CM: Missing the target: Matrix metalloproteinase antitargets in inflammation and cancer. Trends Pharmacol Sci 2013;34:233-242. 


\section{Cellular Physiology Cell Physiol Biochem 2015;37:1210-1218 and Biochemistry Published online: September 30, 2015 $\begin{aligned} & \text { DOI: 10.1159/000430244 } 2015 \text { The Author(s). Published by S. Karger AG, Basel } \\ & \text { www.karger.com/cpb }\end{aligned}$ \\ Zhang et al.: PLGF Regulates Metastasis of NSCLC via MMPg}

11 Dome B, Hendrix MJ, Paku S, Tovari J, Timar J: Alternative vascularization mechanisms in cancer: Pathology and therapeutic implications. Am J Pathol 2007;170:1-15.

12 Bhujwalla ZM, Artemov D, Aboagye E, Ackerstaff E, Gillies RJ, Natarajan K, Solaiyappan M: The physiological environment in cancer vascularization, invasion and metastasis. Novartis Found Symp 2001;240:23-38; discussion 38-45, 152-153.

13 Ferrara N: Vascular endothelial growth factor. Arterioscler Thromb Vasc Biol 2009;29:789-791.

14 Xiao X, Prasadan K, Guo P, El-Gohary Y, Fischbach S, Wiersch J, Gaffar I, Shiota C, Gittes GK: Pancreatic duct cells as a source of vegf in mice. Diabetologia 2014;57:991-1000.

15 Xiao X, Guo P, Chen Z, El-Gohary Y, Wiersch J, Gaffar I, Prasadan K, Shiota C, Gittes GK: Hypoglycemia reduces vascular endothelial growth factor a production by pancreatic beta cells as a regulator of beta cell mass. J Biol Chem 2013;288:8636-8646.

16 Ferrara N, Gerber HP, LeCouter J: The biology of vegf and its receptors. Nat Med 2003;9:669-676.

17 Fischer C, Jonckx B, Mazzone M, Zacchigna S, Loges S, Pattarini L, Chorianopoulos E, Liesenborghs L, Koch M, De Mol M, Autiero M, Wyns S, Plaisance S, Moons L, van Rooijen N, Giacca M, Stassen JM, Dewerchin M, Collen D, Carmeliet P: Anti-plgf inhibits growth of vegf(r)-inhibitor-resistant tumors without affecting healthy vessels. Cell 2007;131:463-475.

18 Autiero M, Waltenberger J, Communi D, Kranz A, Moons L, Lambrechts D, Kroll J, Plaisance S, De Mol M, Bono F, Kliche S, Fellbrich G, Ballmer-Hofer K, Maglione D, Mayr-Beyrle U, Dewerchin M, Dombrowski S, Stanimirovic D, Van Hummelen P, Dehio C, Hicklin DJ, Persico G, Herbert JM, Shibuya M, Collen D, Conway EM, Carmeliet P: Role of plgf in the intra- and intermolecular cross talk between the vegf receptors flt 1 and flk1. Nat Med 2003;9:936-943.

19 Huo X, Li Y, Jiang Y, Sun X, Gu L, Guo W, Sun D: Inhibition of ocular neovascularization by co-inhibition of vegf-a and plgf. Cell Physiol Biochem 2015;35:1787-1796.

20 Jiang H, Wu X, Wang H, Huang C, Zhang L: Combined anti-plgf and anti-endostatin treatments inhibit ocular hemangiomas. Cell Physiol Biochem 2015;36:930-936.

21 Davidson B, Reich R, Risberg B, Nesland JM: The biological role and regulation of matrix metalloproteinases (mmp) in cancer. Arkh Patol 2002;64:47-53.

22 Rhee JS, Coussens LM: Recking mmp function: Implications for cancer development. Trends Cell Biol 2002;12:209-211.

23 Wang R, Ke ZF, Wang F, Zhang WH, Wang YF, Li SH, Wang LT: Golph3 overexpression is closely correlated with poor prognosis in human non-small cell lung cancer and mediates its metastasis through upregulating mmp-2 and mmp-9. Cell Physiol Biochem 2015;35:969-982.

24 Ahmad R, Shihab PK, Jasem S, Behbehani K: Fsl-1 induces mmp-9 production through tlr-2 and nf-kappab / ap-1 signaling pathways in monocytic thp-1 cells. Cell Physiol Biochem 2014;34:929-942.

25 Yang CQ, Li W, Li SQ Li J, Li YW, Kong SX, Liu RM, Wang SM, Lv WM: Mcp-1 stimulates mmp-9 expression via erk 1/2 and p38 mapk signaling pathways in human aortic smooth muscle cells. Cell Physiol Biochem 2014;34:266-276.

26 Zhou X, Qi Y: Plgf inhibition impairs metastasis of larynx carcinoma through mmp3 downregulation. Tumour Biol 2014;35:9381-9386.

27 Zhou X, Qi Y: Larynx carcinoma regulates tumor-associated macrophages through plgf signaling. Sci Rep 2015;5:10071.

$28 \mathrm{Bu}$ J, Bu X, Liu B, Chen F, Chen P: Inhibition of metastasis of oral squamous cell carcinoma by anti-plgf treatment. Tumour Biol 2015;36:2695-2701.

29 Chen Y, Jiang T, Mao A, Xu J: Esophageal cancer stem cells express plgf to increase cancer invasion through mmp9 activation. Tumour Biol 2014;35:12749-12755.

30 Giard DJ, Aaronson SA, Todaro GJ, Arnstein P, Kersey JH, Dosik H, Parks WP: In vitro cultivation of human tumors: Establishment of cell lines derived from a series of solid tumors. J Natl Cancer Inst 1973;51:14171423.

31 Biggs WH, 3rd, Meisenhelder J, Hunter T, Cavenee WK, Arden KC: Protein kinase b/akt-mediated phosphorylation promotes nuclear exclusion of the winged helix transcription factor fkhr1. Proc Natl Acad Sci U S A 1999;96:7421-7426.

32 Bagri A, Kouros-Mehr H, Leong KG, Plowman GD: Use of anti-vegf adjuvant therapy in cancer: Challenges and rationale. Trends Mol Med 2010;16:122-132. 